\title{
Atividade extensionista e TI Verde conectando instituição e comunidade
}

\author{
Mozart Lemos de Siqueira ${ }^{1}$ \\ Cleusa Maria Collares Machado ${ }^{2}$
}

\begin{abstract}
Resumo. A área conhecida como TI Verde alia a evolução da Tecnologia da Informação (TI) à preservação do meio ambiente. Dentre as soluções, é possível listar o aumento da vida útil dos computadores, redução e reciclagem de lixo eletrônico, equipamentos ligados somente enquanto estão sendo utilizados, virtualização e diminuição do consumo de papel em impressões desnecessárias. Nesse contexto, o projeto de extensão apresentado neste artigo faz um levantamento desses aspectos dentro do universo do Centro Universitário Ritter dos Reis (UniRitter), situado em Porto Alegre. Além disso, o artigo faz um balanço do trabalho desenvolvido nos últimos anos e mostra os benefícios para a comunidade.
\end{abstract}

Palavras-chave: TI Verde. Extensão comunitária. Lixo eletrônico.

Abstract. The area known as Green IT combines the evolution of Information Technology (IT) to preserve the environment. Among the solutions you can list the increased lifespan of computers, reduction and recycling of waste electronic equipment connected only while being used, virtualization and reduced paper consumption by printing unnecessary. In this context, the extension project presented in this paper makes a survey of these aspects within the universe of higher education institution know by Centro Universitário Ritter dos Reis, located in Porto Alegre. Furthermore, it shows the benefit to the community.

Keywords: Green Computing. Community extension. E-waste.

\section{Introdução}

Estimativas do Greenpeace [4] indicam que 50 milhões de toneladas de lixo eletrônico são geradas anualmente no nosso planeta. Segundo o Greenpeace, se a quantidade estimada de lixo eletrônico gerado a cada ano pudesse ser colocada em vagões de um trem, esse trem daria uma volta ao mundo. Já o Programa das Nações Unidas para o Meio Ambiente (PNUMA) calcula que a geração de lixo eletrônico global cresce a uma taxa de cerca de 40 milhões de toneladas por ano [6]. No âmbito nacional, o cálculo é de 96,8 mil toneladas de computadores descartados anualmente. Em média, cada brasileiro descarta $0,5 \mathrm{~kg}$ de lixo eletrônico por ano, considerando apenas computadores [5].

O Núcleo de Inclusão Digital (NID), ao qual este projeto está associado, foi criado em 2004 junto à Faculdade de Informática no Centro Universitário Ritter dos Reis. A finalidade do NID é recuperar equipamentos de informática e repassá-los a instituições carentes. Além disso, o núcleo atua no treinamento de informática básica à comunidade do entorno da instituição. Sem perceber, desde o início, já estava sendo realizado um trabalho com apelo ecológico associado ao TI Verde.

\footnotetext{
${ }^{1}$ Curso de Sistemas de Informação, Centro Universitário Ritter dos Reis (UniRitter), Campus Porto Alegre, Rua Orfanotrófio, 555 - Porto Alegre/RS - Brasil

\{mozarts@uniritter.edu.br\}

${ }^{2}$ Curso Tecnológico em Análise e Desenvolvimento de Dados, UniRitter, Campus Porto Alegre.

\{collares@procempa.com.br\}
}

http: //dx.doi.org/10.5335/rbca.2013.3271

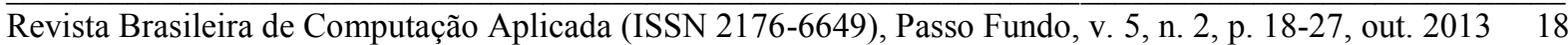


Com a experiência do NID, observa-se que muitos equipamentos de tecnologia são substituídos antes de esgotarem sua vida útil e acabam gerando lixo tecnológico. Esses aparelhos podem ser utilizados por um maior período de tempo pelas próprias pessoas que os descartam ou por terceiros. Assim, o NID busca minimizar o problema do lixo tecnológico por meio de doação dos equipamentos que ainda funcionam ou podem funcionar, com alguns reparos, dando-lhes sobrevida.

Aproveitando o seminário da disciplina de Informática e Sociedade, onde foi apresentado um trabalho sobre o tema TI Verde, o NID foi utilizado como fonte de informações. A partir desse trabalho, surgiu a ideia de um levantamento dentro da instituição sobre aspectos associados à questão.

O projeto de extensão foi proposto no início de 2010 com o objetivo geral de levantar os aspectos relacionados ao TI Verde e, posteriormente, implantar iniciativas que conduzam a instituição em direção a esse processo. Entre diversos resultados esperados, pode-se salientar a economia de bens naturais ao meio ambiente e, também, de recursos para a Instituição, como energia elétrica, por exemplo.

Cabe salientar que muitas empresas estão envolvidas com a prática da TI Verde. Nesse sentido, a Companhia de Processamento de Dados do Município de Porto Alegre (Procempa) pode ser listada como um exemplo de organização que se preocupa com o tema e tem sido fonte de informação. Já a IBM surge como uma referência internacional de companhia preocupada com a TI Verde. Dell e HP também se engajam nessa luta [2]. Outro exemplo de iniciativa nesse contexto é a lista dos 500 supercomputadores com maior poder de processamento e que consomem menos energia, encontrada na Internet em www.green500.org [1].

Neste artigo, aborda-se o trabalho desenvolvido junto ao NID como forma de um balanço de ações dos últimos anos, além dos resultados já obtidos com o projeto de extensão universitária. Na próxima seção, será apresentado o núcleo de inclusão Digital, na seção 3, serão expostos os resultados do projeto extensão universitária de TI Verde. A seção 4 fará um levantamento de alguns aspectos institucionais associados ao TI verde. A conclusão será discutida ao final do artigo, na seção 5.

\section{O Núcleo de Inclusão Digital e a TI Verde}

O NID encontra-se vinculado à Faculdade de Informática e desenvolve atividades de cunho socioeducativo em Canoas e Porto Alegre. Essa abrangência justifica-se por essas cidades abrigarem os dois campi da instituição. Dentre as atividades desenvolvidas, o núcleo oferece oficinas de capacitação em informática (Informática básica, Montagem e configuração de computadores), recuperação e doação de computadores à comunidade carente. O NID ainda trabalha com a ideia de criar multiplicadores, ou seja, alunos de oficinas e atividades tornam-se responsáveis por lecioná-las no futuro.

Os computadores recebidos como doação de empresas, da comunidade acadêmica e do próprio UniRitter são recuperados, montados e configurados no laboratório do NID (espaço disponibilizado pela instituição para acomodar as doações e, também, para realizar os reparos necessários aos computadores para que sejam doados) e, posteriormente, destinados às entidades beneficiadas pelo projeto.

O objetivo principal do NID é universalizar o acesso da população menos favorecida à Informática. Porém, o trabalho desenvolvido pelo NID vem ajudando a natureza, ao postergar a vida útil dos computadores e evitar seu descarte prematuro ou o descarte diretamente na natureza.

As próximas subseções apresentam as principais ações desenvolvidas pelo NID ao longo dos últimos seis anos. Essas iniciativas beneficiaram muitos jovens de baixa renda e devem ser continuadas no futuro, considerando que a instituição valoriza o trabalho de extensão acadêmica.

\subsection{Atividades desenvolvidas pelo NID em 2007}

Abaixo, segue uma listagem das principais atividades desenvolvidas pelo NID no ano de 2007:

- Oficina de Introdução à Informática com crianças carentes dos arredores da Instituição.

- Conserto e entrega de computador para projeto sobre edição de vídeos.

Revista Brasileira de Computação Aplicada (ISSN 2176-6649), Passo Fundo, v. 5, n. 2, p. 18-27, out. 2013 
- Entrega de computadores e montagem de laboratório para a ONG SOS-RIM.

- Retorno de computadores que haviam sido doados pelo NID ao Colégio Guanabara de Canoas, por motivo de falta de uso e necessidade de ocupação do espaço para outras atividades no colégio.

- Projeto de Inclusão Digital com crianças de um projeto da Brigada Militar da Restinga, onde foram ministradas oficinas de Introdução à Informática, Montagem de Computadores, OpenOffice Introdução e Avançado e Uso correto da Internet.

- Oficina de Montagem de Computadores no laboratório do Centro Comunitário Orfanotrófio I (Cencor I).

- Doação de computadores para a Escola Estadual de Ensino Fundamental Brigadeiro Silva Paes.

- Venda de material sucateado do depósito do NID, com auxílio do Departamento de Tecnologia da Informação (DTI).

Cabe salientar dois itens do balanço do ano de 2007. Uma atividade que chamou a atenção foi o retorno da doação de uma escola de Canoas, justificado pela falta de uso dos equipamentos. Esse fato revela um problema que acontece diariamente: onde descartar o lixo eletrônico? Essa escola não estava utilizando os computadores e resolveu devolvê-los para que fossem repassados a outra instituição.

Nações desenvolvidas, também, enfrentam esse problema, porém em escala muito maior. Segundo o Greenpeace [3], todo ano, milhares de computadores e celulares velhos são exportados da Europa, dos EUA, do Japão e de outros países para a Ásia. Lá, os trabalhadores em empresas de sucata - muitos deles, crianças - estão expostos a um coquetel de produtos químicos tóxicos e venenos. Ainda conforme o texto do Greenpeace, Europa, EUA, Japão e outros países despejam o lixo eletrônico na China porque é mais barato do que descartá-lo corretamente. Na Figura 1, são apresentas situações para ilustrar esses fatos. Na imagem da esquerda, uma cena difícil de aceitar, uma criança em meio ao lixo eletrônico. No centro, é apresentada a imagem de uma enorme pilha de teclados à espera da demolição, enquanto a imagem da direita mostra uma carroça sobrecarregada com computadores.

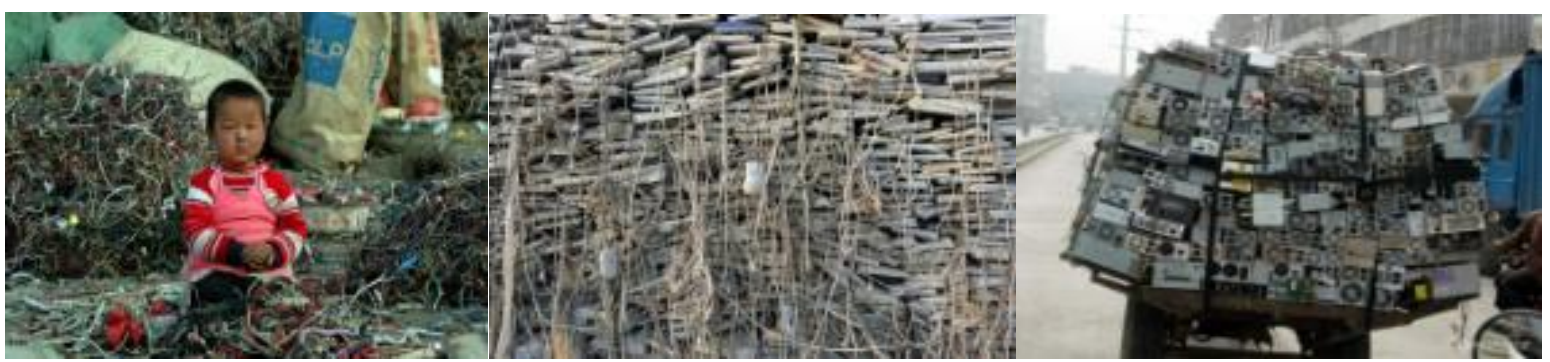

Figura 1: Imagens impactantes sobre destino do lixo eletrônico Fonte: [3]

Outra situação ocorrida nesse ano de 2007 foi a venda de lixo eletrônico para sucata, tendo sido descartadas algumas toneladas de equipamentos que lotaram um caminhão. Nesse ano, ainda não havia preocupação com o destino que seria dado ao descarte do material, coisa que atualmente é uma preocupação constante pelo NID. É provável que parte dessa sucata deva ter sido descartada em algum aterro sanitário algum lixão qualquer. Essa ideia fez repensar o descarte de nossos resíduos de sucata, como será apresentado ao longo do texto.

\subsection{Atividades desenvolvidas pelo NID em 2008}

A seguir, segue uma listagem das principais atividades desenvolvidas pelo NID no ano de 2008:

Revista Brasileira de Computação Aplicada (ISSN 2176-6649), Passo Fundo, v. 5, n. 2, p. 18-27, out. 2013 
- Elaboração do projeto de extensão Aprendizes Digitais, o qual visa à realização de oficinas e cursos sobre software e hardware. O projeto desenvolveu material didático sobre o assunto dos cursos.

- Elaboração do artigo publicado no WEI 2008 - Congresso da Sociedade Brasileira de Computação, divulgando as ações do NID.

- Realização de um curso de Manutenção e configuração de computadores.

- Nesse semestre, o NID foi remanejado para outra sala, situada no quarto andar do prédio de estacionamento. Essa mudança permitiu centralizar os equipamentos que o núcleo administra para doações, pois a sala é mais ampla e oferece melhores condições para manipular e recuperar as máquinas que são repassadas à comunidade.

- Doação de um laboratório de informática, com dez máquinas, para a Escola Aberta Cruzeiro.

\subsection{Atividades desenvolvidas pelo NID em 2009}

Abaixo, segue uma listagem das principais atividades desenvolvidas pelo NID no ano de 2009:

- Curso de Introdução à Informática com jovens carentes da comunidade Orfanotrófio. Foram cinco semanas de curso, com 3 horas semanais, abordando assuntos relacionados à manipulação de programas básicos, como editores de texto e planilha eletrônica, bem como montagem e manutenção de computadores. A Figura 2 apresenta alguns momentos dessa atividade.

- Doação de computadores para o Conselho Municipal do Idoso de Canoas.

- Recebimento de algumas doações de membros da comunidade acadêmica.

- Organização e doação do laboratório da comunidade Orfanotrófio, com dez máquinas. Esse laboratório deve ser utilizado para cursos pela comunidade. A Procempa deve disponibilizar o ambiente de rede para conectar essas máquinas à Internet, além disso, deve oferecer alguns cursos.

- Doação de dez computadores para o Centro de Referência Especializado de Assistência Social (Creas) de Canoas.

- Doação de dez computadores para a Fundação de Atendimento Socioeducativo (Fase), utilizados para equipar o laboratório de informática.

- Ao longo do semestre, o NID deu suporte para a manutenção do laboratório da Escola Aberta Vila Cruzeiro.
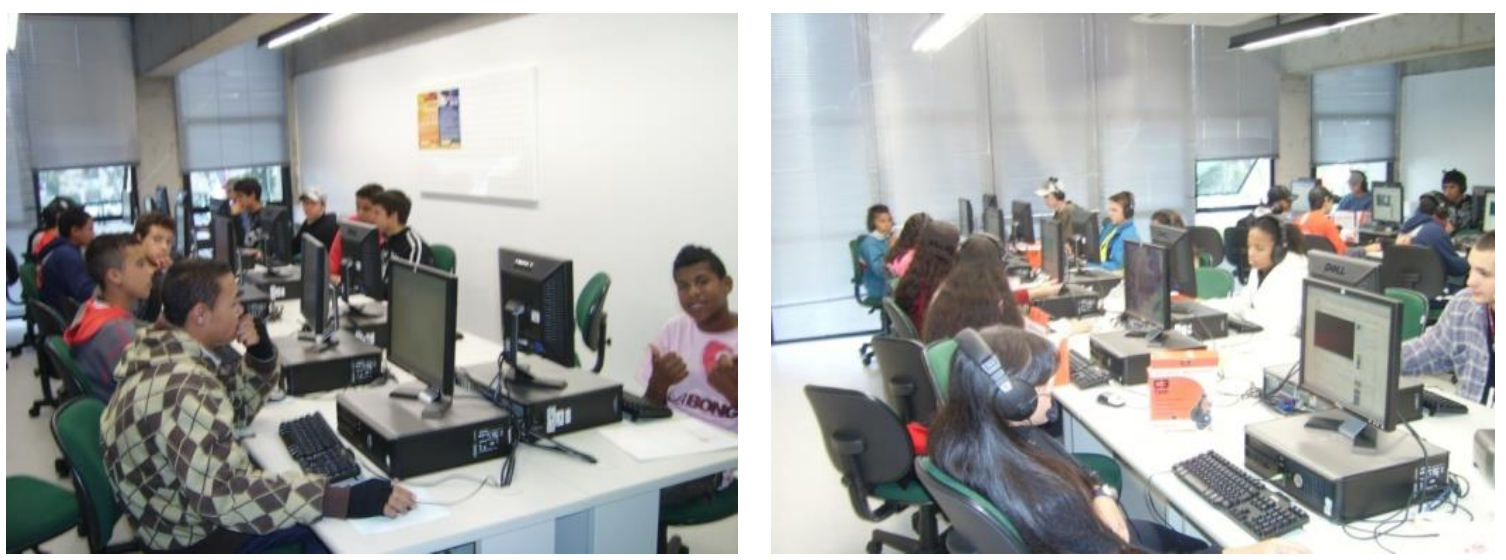

Figura 2: Jovens participando do curso de Introdução à Microinformática, nos laboratórios da instituição 


\subsection{Atividades desenvolvidas pelo NID em 2010}

Abaixo, segue uma listagem das principais atividades desenvolvidas pelo NID no ano de 2010:

- Doação de dez computadores e um notebook à Fundação de Atendimento Socioeducativo (Fase - Case PC) em Porto Alegre.

- Inauguração da Sala de Inclusão Digital do Centro Comunitário Orfanotrófio I (Cencor I) em Porto Alegre. Na Figura 3, são apresentadas imagens do evento.

- Curso de Introdução à Informática no laboratório do Cencor I.

- Doação de 30 computadores para a Agência Adventista de Desenvolvimento de Recursos Assistenciais em Porto Alegre.

- Doação de dez computadores para o Instituto Espírita Irmãos de Boa Vontade.

- Repasse de $1.710 \mathrm{~kg}$ de lixo eletrônico para a empresa Otser. A Figura 4 apresenta o certificado de descarte emitido pela Otser, sob número 561;
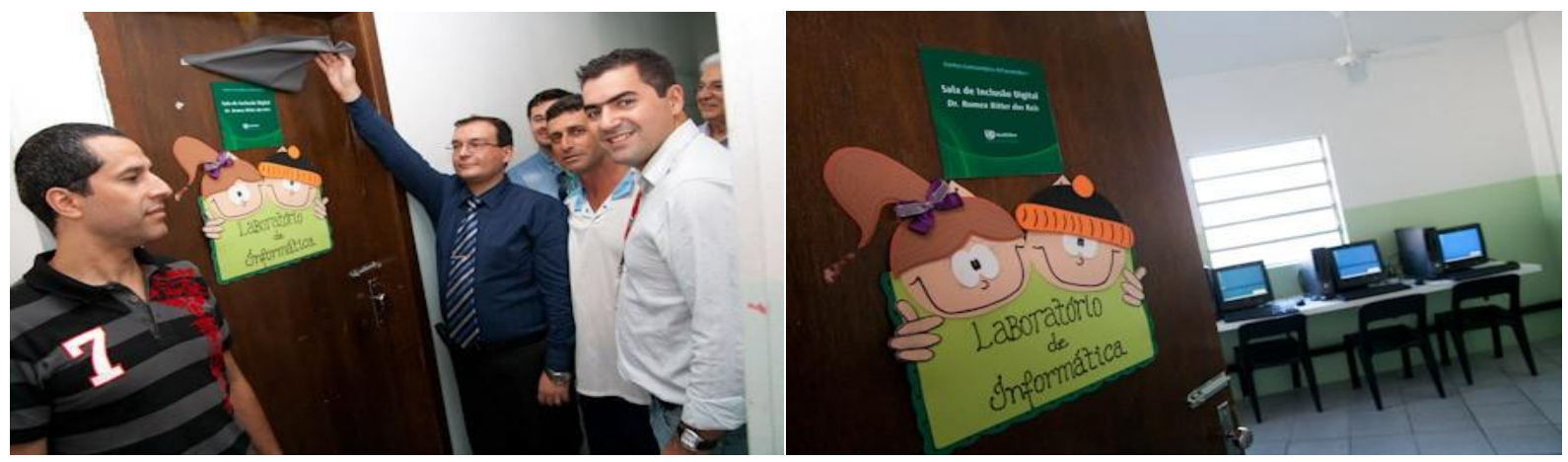

Figura 3: Inauguração da Sala de Inclusão Digital do Cencor I

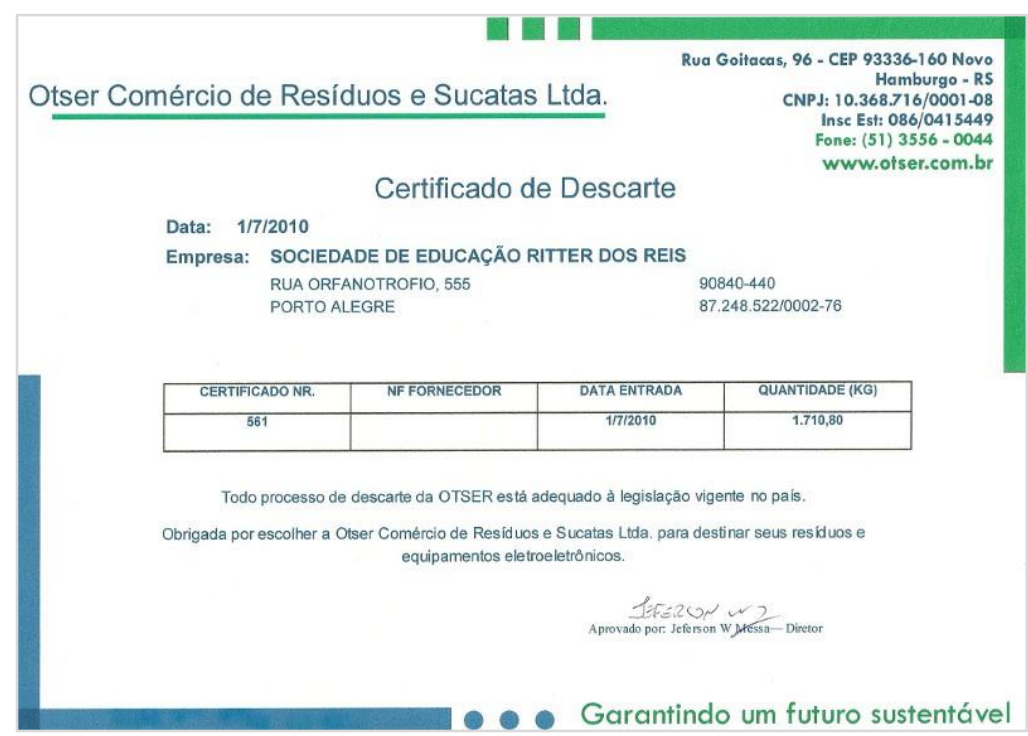

Figura 4: Certificado de descarte de lixo eletrônico 
Em 2010, um dos primeiros frutos do projeto de TI Verde foi o repasse do material sucateado do NID a uma empresa especializada em reciclagem de lixo eletrônico, um descarte consciente, diferente do ocorrido nos anos anteriores. A empresa escolhida para o repasse dos restos de lixo eletrônico do NID chama-se Otser e fica situada no município de Novo Hamburgo. Segundo os proprietários da empresa (http://www.otser.com.br), o que ainda não é possível reciclar é guardado para quando houver processos de reciclagem. Ainda com base em informações da empresa, sabe-se que em torno de $98 \%$ dos computadores já são reciclados.

\subsection{Atividades desenvolvidas pelo NID em 2011}

Abaixo, segue uma listagem das principais atividades desenvolvidas pelo NID no ano de 2011:

- Doação de cinco computadores à Comunidade Terapêutica Nova Esperança de Santa Rita/RS.

- Doação de 20 computadores para a Escola de Ensino Médio para Surdos Profa. Lilia Mazeron.

- Doação de cinco computadores para o Instituto Enio (um pequeno desejo).

- Doação de dez computadores para a Escola Estadual Dr. João Batista de Lacerda em Porto Alegre/RS.

- Repasse de 573,63 kg de lixo eletrônico para a empresa Otser. A empresa retornou certificado de descarte.

Uma das lacunas que o NID deixou de preencher está associada ao treinamento de jovens carentes para atuar na área de microinformática. No entanto, essa sempre foi uma das linhas de atuação do núcleo e deverá ser retomada.

\subsection{Atividades desenvolvidas pelo NID em 2012}

Abaixo segue uma listagem das principais atividades desenvolvidas pelo NID no ano de 2012:

- Doação de 20 computadores para a Escola Estadual de Ensino Fundamental Irmão Miguel Dario em Porto Alegre.

- Doação de 20 computadores para o projeto de regularização fundiária da Secretaria Municipal de Desenvolvimento Urbano de Canoas.

- Doação de 40 computadores e quatro impressoras para o Território da Paz, projeto conduzido pela Secretaria Municipal de Segurança Pública e Cidadania da Prefeitura de Canoas.

- Doação de 40 computadores para o $4^{\circ}$ RPMON da Brigada Militar.

- Doação de dez computadores para a Escola Estadual de Ensino Fundamental Fátima de Canoas/RS.

- Doação de dez computadores para a Associação Brasileira de Profilaxia.

- Doação de um computador para o Grupo Escoteiro Lanceiros Negros de Porto Alegre.

- Doação de 20 computadores para o $1^{\circ}$ BPM da Brigada Militar. Esses computadores serão utilizados em um projeto social em Porto Alegre.

\subsection{Atividades desenvolvidas pelo NID em 2013}

A seguir, segue uma listagem das principais atividades desenvolvidas pelo NID no ano de 2013:

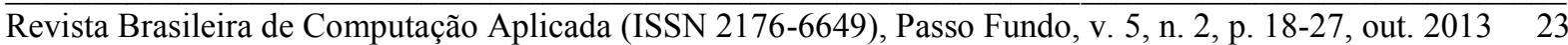


- Doação de 20 computadores para o projeto de regularização fundiária da Secretaria Municipal de Desenvolvimento Urbano de Canoas (Figura 5).

- Doação de 15 computadores para a Escola Estadual de Ensino Fundamental João XXIII em Canoas.

- Doação de 15 computadores para a Escola Estadual de Ensino Fundamental Dr. Victor Hugo Ludwig em Canoas.

- Doação de três computadores para a Associação Canoense - Casa Lar do Idoso.

- Doação de 20 computadores para a ACM Cruzeiro do Sul em Porto Alegre.

- Doação de 12 computadores para a Escola Municipal de Ensino Fundamental José Loureiro da Silva em Porto Alegre.

- Doação de três computadores para a Escola Municipal de Ensino Fundamental Rondônia em Canoas.

- Doação de 20 computadores para a Associação dos Moradores e Amigos da Vila Tronco Neves e Arredores - Amavtron.

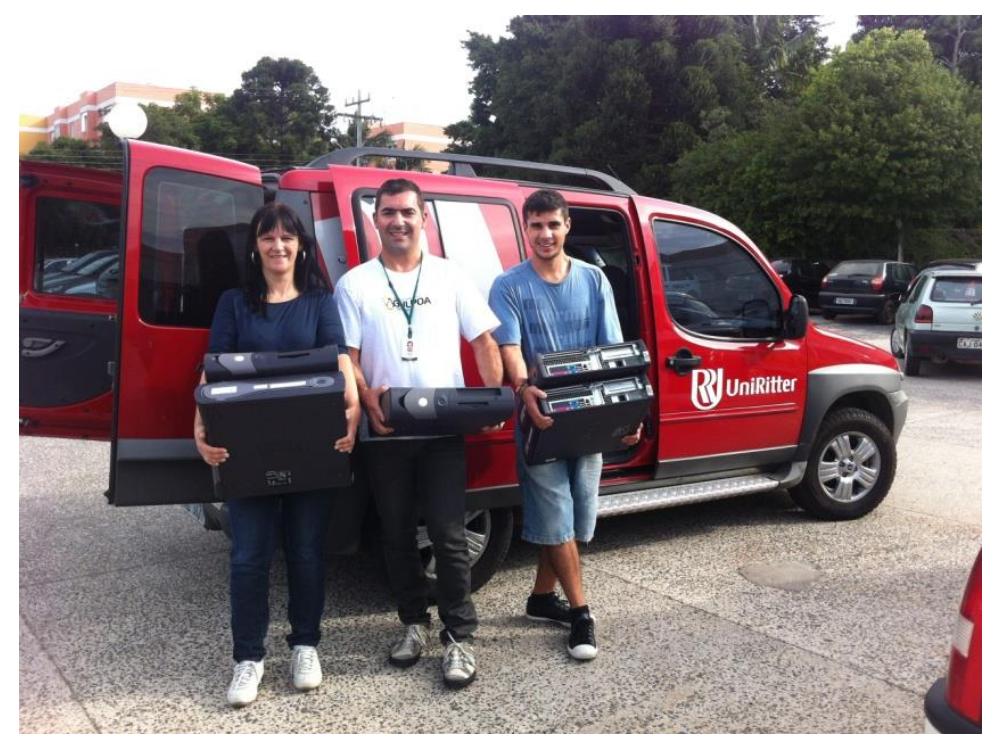

Figura 5: Imagem da entrega dos computadores na Secretaria Municipal de Desenvolvimento Urbano de Canoas

\section{Resultados do Projeto de Extensão Universitária de TI Verde}

Um dos primeiros resultados atingidos pelo projeto de TI Verde junto ao NID foi a conscientização de que as atividades do núcleo são atividades de TI Verde e, portanto, devem ser valorizadas. A principal ação, nesse sentido, foi o repasse de computadores, que não poderiam ser reaproveitados, pois já eram sucata, para uma empresa especializada em reciclagem, conforme apresentado na seção 2.4.

Nesse contexto, foi elaborada uma estratégia para motivar a comunidade acadêmica a desfazer-se do lixo eletrônico acumulado em casa, seja um computador antigo, uma peça ou mesmo um telefone celular que não é mais utilizado. A ideia foi promover anualmente uma semana durante a qual as pessoas descartem seu lixo eletrônico doméstico e o repassem para que seja enviado à reciclagem, ou recuperado para a doação. Essa atividade, que tem sido desenvolvida durante a semana acadêmica da Faculdade de Informática, é chamada de Semana de Coleta de Lixo Eletrônico; além disso, em qualquer período do ano, qualquer um pode entregar lixo eletrônico ao NID, pois o posto de coleta é permanente.

Dentro do plano de conscientização da comunidade acadêmica para o lixo eletrônico e a TI Verde, a edição de julho de 2010 da Revista Conexão apresentou uma matéria sobre o tema [5]. Nessa reportagem, foi 
divulgada para a comunidade acadêmica a problemática do lixo eletrônico, focando o tema da sustentabilidade e difundindo o trabalho do NID para a comunidade.

\section{$4 \quad$ Levantamento da infraestrutura institucional associada ao TI Verde}

O universo da TI Verde dentro da Instituição está sendo catalogado para a divulgação à comunidade externa sobre o quanto é feito para ajudar a economizar recursos naturais. Iniciativas simples podem representar economia de energia elétrica. Cabe salientar que essas ações não têm relação com esse projeto, pois já existem no UniRitter desde antes de este ser desenvolvido.

Abaixo, segue uma relação de iniciativas que podem ser observadas em um passeio pelo campus de Porto Alegre:

- Temporizadores nas torneiras e nas lâmpadas de todos os banheiros:
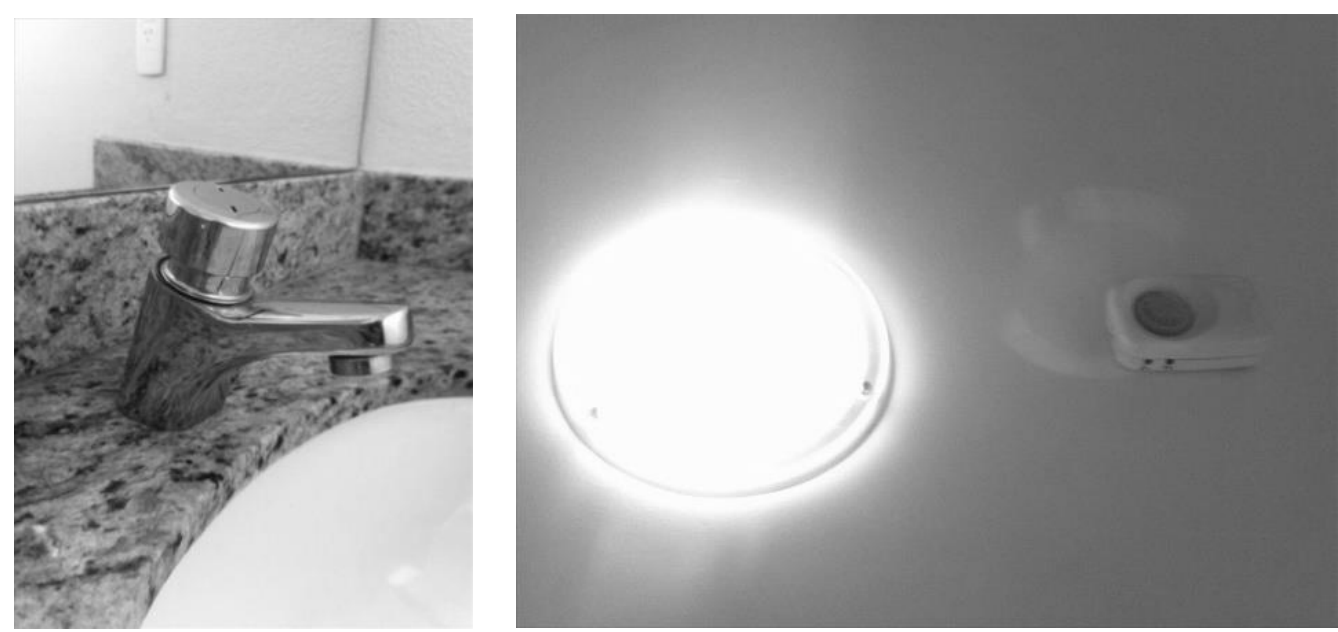

Figura 5: Torneira e lâmpadas com temporizador

Iluminação natural dentro dos prédios, reduzindo o consumo de energia durante o dia:

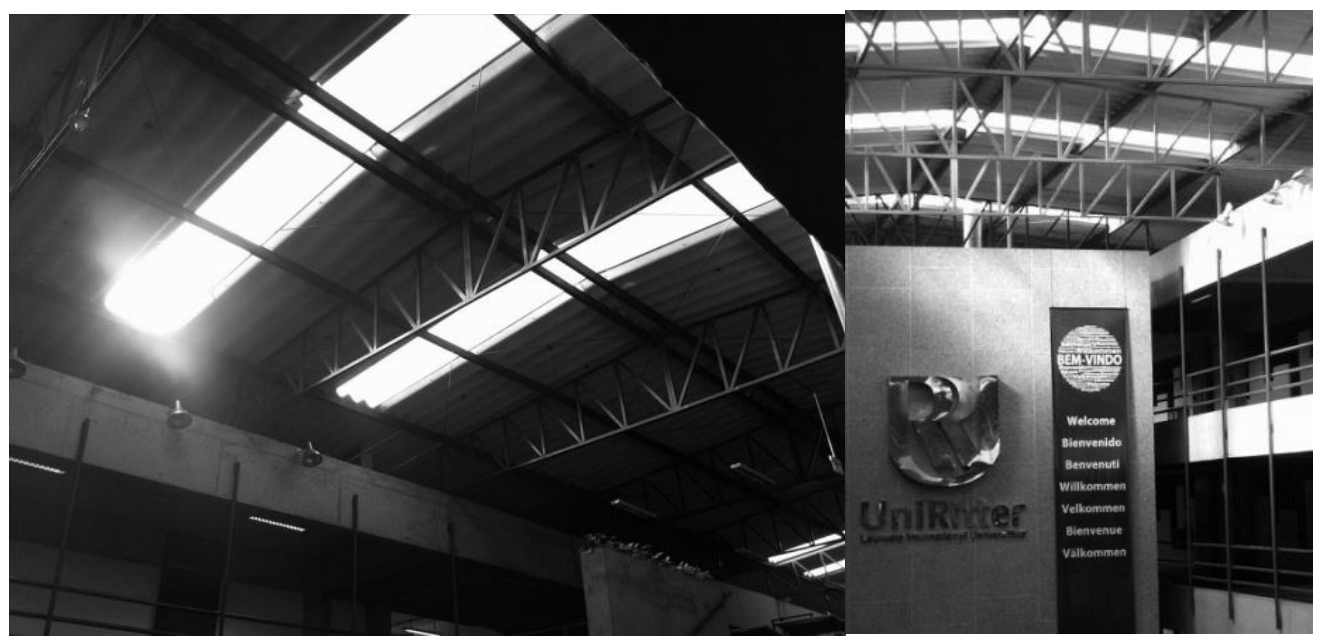

Figura 6: Imagens do interior do prédio A, com luz natural 
Em um passeio pelo campus de Porto Alegre, é possível observar as iniciativas da instituição em relação à ecologia. Nesse sentido, esse projeto de extensão visa a divulgar essas ações e mostrar à comunidade que é uma empresa "Verde" e que se preocupa com as futuras gerações.

Uma dificuldade encontrada foi quanto a mensurar a economia, visto que não se teve acesso aos números dos gastos, e, como não houve parâmetro para comparação, esse aspecto não foi apresentado neste artigo. Esse pode ser um tema para trabalhos futuros.

- Lixeiras seletivas nos corredores da instituição:

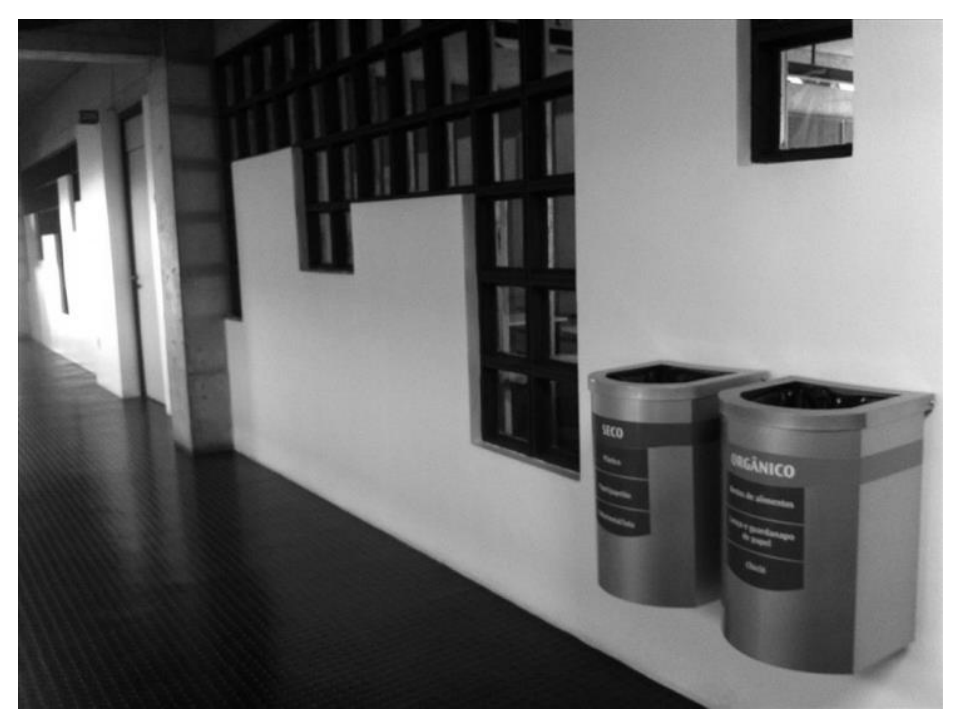

Figura 7: Lixeiras seletivas nos corredores

\section{$5 \quad$ Conclusões}

O projeto desenvolvido dentro do NID desde 2004 tem grande importância no contexto ecológico e deve ser valorizado como tal. Porém, a área de TI Verde tem evoluído com novos processos e iniciativas de empresas de reciclagem, sendo importante alinhar o trabalho realizado com as técnicas associadas ao TI Verde, expandindo os benefícios. Isso é observado com a iniciativa de repassar o que é lixo para uma empresa especializada.

Um dos próximos passos almejados pelo projeto está associado à eficiência energética, verificando dentro da instituição os gastos com energia e os desperdícios que poderiam ser eliminados. Considerando-os como grandes consumidores de recursos tecnológicos e naturais, os laboratórios de informática serão estudados. Há, ainda, a ideia de desenvolver projetos de reciclagem de materiais de computadores descartados. Essa reciclagem poderia ser feita por meio de artesanato e divulgada para as comunidades apoiadas pela instituição.

Um dos trabalhos futuros que devem ser implementados nos próximos semestres é a retomada das doações, visitando as entidades beneficiadas para verificar a utilização e a abrangência dos computadores em termos do universo de pessoas beneficiadas. Essa medida tem o intuito de avaliar o trabalho do NID e dar um retorno à UniRitter, considerando o apoio que tem dado a essa iniciativa nos últimos anos. 
A iniciativa de um Núcleo de Inclusão Digital dentro de uma instituição de ensino não é uma prática comum, mas poderia gerar excelentes resultados caso fosse adotada como regra. A experiência nesse assunto mostra que não só a comunidade é beneficiada, como também a própria instituição.

\section{Referências}

[1] AFONSO, R. Supercomputadores têm eficiência energética 15\% maior. 2009. Disponível em: $<$ http://computerworld.uol.com.br/tecnologia/2009/07/17/supercomputadores-tem-eficiencia-energetica-15maior> Acesso em: 15 jun. 2013.

[2] CORREIRA, E. F. C. TI Verde. 2008. Disponível em: $<$ http://www.esteio.com.br/downloads/pdf/ti_verde.pdf $>$ Acesso em: 12 jan. 2010.

[3] GREENPEACE. Greener Electronics. 2010. Disponível em: <http://www.greenpeace.org/international/ en/campaigns/toxics/electronics/> Acesso em: 13 jun. 2013.

[4] GREENPEACE. The E-Waste Problem. 2005. Disponível em: <http://www.greenpeace.org/international/ campaigns/toxics/electronics/the-e-waste-problem/> Acesso em: 15 jun. 2013.

[5] ORTÁCIO, S. A sustentabilidade como meta das tecnologias de informação. Revista Conexão, Porto Alegre, v. 36, p. 20-21, jul./ago. 2010.

[6] PALOP, J. Geração de lixo eletrônico cresce a $40 \mathrm{mi}$ de toneladas por ano. 2010. Disponível em: $<$ http://www.pnuma.org.br/noticias_detalhar.php? id_noticias=224> Acesso em: 17 jun. 2013.

[7] TROIS, V. PROCEMPA Tecnologia para uma vida sustentável. 2009. Disponível em $<$ http://www.procempa.com.br/procempa_verde.pdf> Acesso em: 22 jan. 2010. 